\title{
MODELLING AND FORECASTING CENTRAL HELSINKI OFFICE RENTS
}

\author{
Sami KIEHELÄ a,*, Heidi FALKENBACH ${ }^{\text {a }}$ \\ ${ }^{a}$ Real Estate Research Group, Department of Real Estate, Planning and Geoinformatics, Aalto \\ University, School of Engineering, P.O. Box 15800, FI-00076 Aalto, Finland
}

Received 29 May 2012; accepted 18 May 2013

\begin{abstract}
Office market modelling has attracted a mounting amount of interest among researchers and practitioners during past decades. Growing research activity in the area is not surprising considering the importance of rent on property values. Nonetheless, very little quantitative research on Finnish rental markets has been carried out. The objective of this study is to respond to that lack of research by examining office rent determination in the Helsinki central business district (CBD) in reduced form single equation context. We discover that changes in central Helsinki office rents are subject to variations in new office completions and changes in the added value of services sector. As historical fit does not necessarily translate into a satisfactory predictive fit, the forecasting adequacy of the final model is also tested by constructing out of the sample forecast over 2007-2009. We find that the model outperforms two naïve forecasting methods, but fails to perfectly trail the actual index.
\end{abstract}

KEYWORDS: Office rent; Real estate investment; Modelling; Forecasting; Helsinki

\section{INTRODUCTION}

There has been significant interest in office market modelling in recent decades. Existing research has generated a variety of alternative models, adopted a number of new methodologies and provided substantial insight into the workings of real estate markets. Much of that research was in the first place carried out for North American office markets by such researchers as Rosen (1984), Hekman (1985), Wheaton (1987) and Wheaton and Torto (1988). The practice soon disseminated outside the US, and the models were further developed and introduced in new markets, particularly in the UK. In fact, UK office markets have since then attracted a tremendous amount of research interest, including studies by Dobson and Goddard (1992), Keogh (1994), RICS (1994), McGough and Tsolacos (1995), Hendershott et al. (1999), Farrelly and Sanderson (2005) and Hendershott et al. (2010). In recent years, the growing importance of the property markets in large Asian metropolises has also triggered office market research on that end, including studies by Ho (2005) and Hui and Yu

\footnotetext{
* Corresponding author. E-mail: sami.kiehela@aalto.fi
}

(2006) on Hong Kong, Ng and Higgins (2007) on Singapore, and Ke and White (2009) on Shanghai markets.

The development of office market modelling does not only appear in increasing geographical coverage but also in alternative directions the researchers have taken. In rather broad terms, two different paths have emerged. First, a number of studies have focused on explaining the workings of the entire office market in a simultaneous equation context. These systems encompass several interconnected equations for different market variables such as rent, vacancy rate, and construction activity. This direction has been followed by, among others, Rosen (1984), Hekman (1985), Wheaton (1987), Wheaton et al. (1997), Hendershott et al. (1999), Ho (2005), and Hui and Yu (2006). Many of these studies, however, face a common obstacle of poor data availability, which undermines much of the applicability of these data intensive models.

By contrast, studies of the alternative direction chiefly attempt to model a single office market variable one at a time. While these studies have undisputedly concentrated on rental modelling, a variety of methodologies have been tapped. Arguably the most popular method has been a reduced 
form single equation specification employed by researchers such as Dobson and Goddard (1992), D'Arcy et al. (1999), White et al. (2000), Orr and Jones (2003), Karakozova (2005), Ng and Higgins (2007). In addition, variations in office rents have been explained in several more advanced methodologies, such as vector autoregressive (VAR) and vector error correction (VEC) models, including the studies by Hendershott et al. (2002a, 2002b), Farrelly and Sanderson (2005), Mouzakis and Richards (2007). In addition, Stevenson (2007) extended Hendershott et al. (2002b) model to explore the relationships between distinct central London submarkets.

Notwithstanding the rapid development of the office market research, many small, more peripheral office markets in Europe still chiefly remain under-researched. Naturally, exceptions to this trend exist, but generally speaking, far more research is needed. Regardless of the commendable work of McGough et al. (2000) and Karakozova (2005), the Helsinki office market does not make an exception in that respect. In fact, as a result of rapid market development during the past decade, much of the relevance of the results documented in those studies is questionable today. Moreover, the availability of longer constant quality time series itself may help in gaining a new insight into the Helsinki office market.

The aim of this article is to contribute to the literature on rental modelling by constructing a theoretically sound and statistically adequate reduced form single equation model incorporating various supply-side and demand-side variables. In single equation content, it is assumed that there are certain exogenous demand and supply side variables that linearly explain an endogenous variable, rent, in the short run. This study aims to delineate those demand and supply variables that have the most significant impact on rent adjustment process. In addition, the study intends to add to existing literature by investigating the importance of three alternative demand side proxies in office rent determination, one being added value of services sector that, to the authors knowledge, has not been successfully incorporated in similar models in the past. The purpose of this paper is also to expand the geographical reach of the rental modelling research from the core European markets into one of the under-researched office markets of Helsinki. Moreover, the paper is motivated by the dramatic changes in the Helsinki office market over the past decade. Internationalisation of the market, a construction boom, and a completely changed vacancy environment may have led to changes on how different demand and supply variables explain office rents. Finally, this paper aims to investigate the forecasting ability of the model by utilising the sample forecasting methodology.

The remainder of the paper is organised as follows. After this introductory section, the study continues with a discussion of the relevant variables in the existing rental modelling literature within the single equation context. Thereafter, the Helsinki metropolitan area office market is briefly discussed to establish the foundations for the study. In the following section, an initial formulation of the central Helsinki office rent model and data of the current study are presented and discussed. The model is estimated and the final specification is selected based upon the relevant diagnostic tests in Section . Subsequently, forecasting accuracy of the estimated model is evaluated and discussed in the following section. Finally, the paper is summed up with a concluding section.

\section{WHAT DRIVES OFFICE RENTS}

One of the earliest attempts to explain the determinants of office rents was carried out by Gardiner and Henneberry (1989). They argue that a single, national model is of limited practical applicability, and England was split into eight regions which each having individual specifications estimated. To allow for interrelationships between regional and national economies, all variables were expressed as a percentage of the corresponding national figures. Substantial differences between the regions were documented. It was found that the model proves significant for the four healthy regional economies, whereas the four declining regions exhibited contrary behaviour. Gardiner and Henneberry (1989) suggest that gross domestic product and stock of floor space variables are to be included in the model even though the validity of incorporating the gross domestic product variable is dubious due to negative signs for two of the regions.

Dobson and Goddard (1992) examine both price and rent of three alternative property types in the regional context in England. In their attempt to explain rent variations, they use employment in the financial services sector as a proxy for economic activity. In addition, house prices and longterm interest rates are incorporated in the study. Unambiguous supply-side proxies, such as a measure of construction activity, are left out, however. Interestingly, it is concluded that financial sector employment fails to explain office rent variations, 
whereas house prices have a strong impact on office rents. The long-run interest rate variable demonstrates a statistically significant inverse relationship in office rent determination. Albeit house prices display robust capability in explaining office rents, on theoretical grounds the connection remains dubious to the authors of the current study.

In contrast to a regional approach within a single nation, Giussani et al. (1993) apply a simple regression model of office rents within ten major European economies. The paper investigates GDP, unemployment, service sector employment, real long-term interest, and economic uncertainty as demand-side variables. Similar to Dobson and Goddard (1992), supply-side proxies are completely omitted due to lack of sufficient and consistent data across the cities under investigation. The authors conclude that rental variations in two of the examined locations are not explained by any of the demand-side proxies. Furthermore, service sector employment and the interest rate variable appear significant only once, whereas unemployment performs only slightly better, being significant in three cases. While changes in real GDP explain rental movements in seven out of ten cities, the coefficients of determination remain fairly low, ranging between 0.26 and 0.63 . Notwithstanding the somewhat disappointing results, the study proposes that variations in office rents of European metropolises can be explained by broad demandside proxies such as GDP. Despite of increased European market integration over the past decade, the studied markets yet vary significantly spatially and represent different economic climates proposing also need for more local level of investigation.

Quite similar results to those of Giussani et al. (1993) are documented by D'Arcy et al. (1997), who studied rent determination of 22 European cities in a time-series cross-sectional analysis. It is found that gross domestic product and real interest rates prove significant in the rental adjustment process, while supply side factors are not investigated at all. In addition, market size effect on rent determination is investigated, but no significance can be reported.

D'Arcy et al. (1999) examine the impact of the interaction of demand and supply side variables on office market rents in the Dublin area. They conclude that changes in office rental levels are driven by changes in real GDP in the preceding period and changes in new office supply in the preceding three periods. Surprisingly, the service sector employment variable is not found to affect changes in real rents with any lag. The writers argue that the model succeeds to catch the long-run changes in real rents but fails to capture an extraordinarily sharp spike in rents during the test period.

Orr and Jones (2003) propose that office takeup is the best measure of demand, and hence ought to be incorporated in a reduced form demand supply specification. The authors acknowledge that take-up quantifies only satisfied demand, which implies that unsatisfied demand is not taken into account and results in inclusion of a measure of general economic activity to capture the unsatisfied part of the demand. Empirical results propose that the general economic activity variable does not turn out to be statistically significant, whereas the take-up variable does. However, the authors acknowledge that regressions for both cities have a relatively poor historical fit and the forecasting ability of the model is not at a satisfactory level. In addition to the single equation price equation, Orr and Jones also undertake a three-equation structural model approach, which in fact prove to provide a rather strong historical fit.

Karakozova (2005) adopts a simple single equation regression method capturing supply and demand side variables affecting the rent adjustment process. She concludes that rental growth in Helsinki is best explained by contemporaneous changes in service sector employment and in the output in financial and business services, by changes in GDP with a one-year lag and by new office building completions with a two-year lag.

As several Asian cities have developed rapidly during past decades and increased their importance in the portfolios of investors around the globe, much of the property market research has also shifted its focus to the markets in that region. Even though the development has been fast, researchers endeavouring to examine these markets still face significant problems with data availability, its reliability and length of times series, as pointed out in the papers of $\mathrm{Ng}$ and Higgins (2007) and Ke and White (2009). Despite the data challenges, Ng and Higgins (2007) model rent adjustment process in Singapore office market with the reduced form demand-supply specification. Their findings propose that changes in office rents in Singapore are $72 \%$ explained by contemporaneous changes in construction costs and financial, insurance and real estate employment, changes in the prime lending rate in the preceding period, and changes in the vacancy rate two periods before. It is noteworthy that in contrast to previous existing literature (for example, D' Arcy et al. 1999; Karakozova 2005), changes in gross domestic product is 
not found to have a statistically significant impact on office rent determination. Nor is office supply included in the final specification, which may reflect the weakness of the data used as a proxy for supply.

\section{HELSINKI OFFICE MARKET DEVELOPMENT IN THE FIRST DECADE OF THE 2000S}

The Finnish property market has undergone a tremendous change during the first decade of the millennium. Foremost, rapid internationalisation of the Finnish real estate market began in the early 2000s when international investors made their initial acquisitions in Finland. Since then, the number of foreign investors has increased to more than 70 (KTI 2010). Much of the international investment demand has focused on office properties in the capital area, arguably the most liquid and transparent real estate segment in Finland.

The Helsinki area office market covers approximately 8.5 million square metres of office space, of which more than 400,000 square metres are in the Helsinki central business district (CBD) (Catella 2012), undisputedly the most important single office submarket in Finland. Helsinki CBD houses a variety of private office occupants, such as law firms, consultants, accounting firms, investment and commercial banks, and several corporate headquarters. In addition to private occupants, Helsinki CBD provides premises for several government agencies and ministries, not to mention local government offices as evidenced in Figure 1. Helsinki CBD (city districts of Kluuvi, Kaartinkaupunki and Kamppi) workplace structure in 2008 (City of Helsinki Statistics 2012). A vast majority of Helsinki CBD workplaces are either in private services (excluding trade) or in public services.

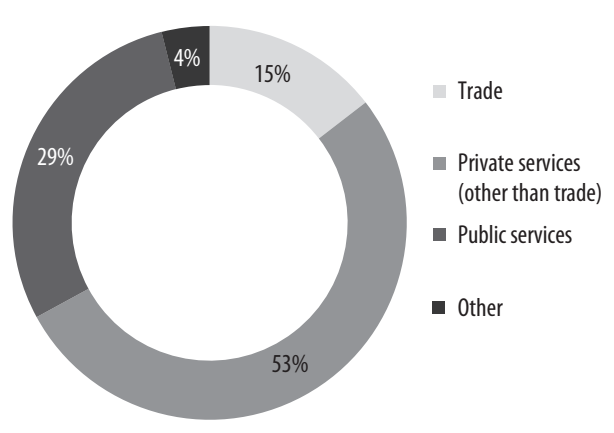

Fig. 1. Helsinki CBD (city districts of Kluuvi, Kaartinkaupunki and Kamppi) workplace structure in 2008 (City of Helsinki Statistics 2012)
In the wake of the 2000s, the Helsinki area office market was characterised by a very low (under $2 \%$ ) vacancy rate. In the course of the first decade of the new millennium, office vacancy has climbed and in late 2009, vacancies already stood at the $12 \%$ level. While the vacancy level in the capital region offices soared during the first decade of the 21st century, the Helsinki CBD office vacancy rate remained relatively modest, mostly below 5\% throughout the period (Catella 2012). Generally, Helsinki CBD provides very few new office development opportunities and is characterized by a virtually non-existing new office supply, which supports a continuously low CBD vacancy rate. In contrast, the more peripheral Helsinki area office submarkets witnessed massive office construction thanks to foreign investors' appetite for new investments. Cross-border capital inflow led to record low yields and made many developments profitable and inflated the office supply.

\section{INITIAL FORMULATION OF THE HELSINKI CBD RENTAL OFFICE MODEL}

In determining the Helsinki CBD office rents, a reduced form single equation method was selected, as it allows for constructing a model that relies on underlying theory but can be effectively applied in practice. Also, as poor data availability remains a limitation in real estate research (for example Orr, Jones 2003; D'Arcy et al. 1999), a model that is less intensive of a priori information is considered more desirable. In addition, there is no unambiguous evidence that more complex models, such as simultaneous equation specifications, can provide a more robust forecasting outcome supporting the use of a simpler single equation methodology (see, e.g. Stevenson, MacGarth 2003; Karakozova 2005).

Selection of the independent variables used in the current reduced form demand supply model is supported by the findings of the previous research. As documented by several researchers (Gardiner, Henneberry 1989; Giussani et al. 1993; D'Arcy et al. 1997; D'Arcy et al. 1999; Karakozova 2005), gross domestic product has consistently outperformed other demand-side variables in explaining office rental variations. This is theoretically sound because during economic expansion, firms produce an increasing amount of goods and services, which in turn leads to a greater needs for production, such as labour and space. To accommodate the expanding business, firms seek larger premises, which underpins the occupant's demand for space. 
Gross domestic product is a very broad measure of demand, involving the entire spectrum of economic activities from agriculture to manufacturing. However, because demand for office use relates particularly to the needs of businesses that use office premises to house their activities, a narrower activity variable of gross added value of service sector (vas) is included. As a component of gross domestic product, this variable includes the added value of different services, both public and private, in the context of the national economy. It is believed that as a distinctive service sector activity measure, it is able to delineate the demand for office space particularly well.

The third demand-side variable to be included in the initial model is employment in financial, real estate and business services (emp), which is a significant office user group and variations in its employment induces changes in the office demand. Inclusion of this measure is also supported by the encouraging findings of other researchers, such as Karakozova (2005) and Ng and Higgins (2007), who adopt similar employment variables. Furthermore, the use of alternative employment variables has gained wide support in a multi-equation context, which, for its part, proposes the incorporation of the employment variable (see Hendershott et al. 1999; Tse, Webb 2003).

On the supply side, four different variables are introduced. Albeit the general shortcomings of the supply side data, D'Arcy et al. (1999) and Karakozova (2005) document that new office supply (office completions) proves significant in the rental adjustment process. Hence, new office completions in the Helsinki area (cons) are included in the current model. It is noted that construction flow variables, such as office completions, are not perfect measures of office supply as they do not necessarily account for the space that is withdrawn from the market. This is also the case in the current study and therefore the use of the stock variable, which considers both the space entering and exiting the market could overcome this obstacle. In response, the office stock (os) variable is incorporated in the model.

Both of the aforementioned variables consider space as part of supply only when it is physically available in the market. Consequently, planned and uncompleted office developments are not taken into consideration. This conflicts with the reality because uncompleted projects are typically available as pre-lets before the start of and during the construction works. To tackle this problem, office construction starts (starts) will be included in the model, as they should be able to capture at least a portion of the pre-let supply.

Although the use of vacancy rate (vac) has been constrained by the poor data availability in many single equation studies (for example D'Arcy et al. 1999), significant empirical support exists in the simultaneous equation modelling context for the inclusion of the vacancy rate variable (Rosen 1984; Wheaton et al. 1997; Tse, Webb 2003). In single equation content, the findings of $\mathrm{Ng}$ and Higgins (2007) also propose the incorporation of the vacancy rate as a supply side variable. The authors acknowledge that it can be argued that similar with rent, a vacancy is endogenous variable, a result of demand supply interaction and therefore should not be included in single equation model of rent. However, vacancy also demonstrates the quantity of space available for lease at each point in time, and hence there is sound theoretical support for the inclusion the variable as supply side proxy. Finally, motivated by the earlier research and fairly good data availability, the vacancy variable is included in the model.

When office users face changes in their business environment, they typically first adjust the operations within existing premises by tightening or allowing a short-term internal vacancy rather than immediately relocating to more suitable premises. Hence, only sustained changes in space needs eventually bring about an altered demand for space. Arising from this, adjustments in occupant demand typically lag behind variations in overall economic activity. Similarly, on the supply side, even though new office space comes to the market, users are unable or unwilling to react immediately. Users may be constrained by the current lease agreement, or the cost of moving may invalidate the benefits of relocating, resulting in the lag. To accommodate the lagging effect, lagged values of up to six periods (three years) will be included in the current model, and hence the most appropriate lag structure will be determined by the data.

Arising from the above, a single equation model of central Helsinki office rents can be specified as a function of three demand $(D)$ and four supply $(S)$ side variables. Positive and negative signs after the variables in Equation (1) exhibit a priori expectations of individual variables' impact on the rent. Generally, demand side variables are expected to have a positive effect on rent ceteris paribus in contrast to the inverse relationship between supply side variables and rent. A positive relationship of demand proxies is anticipated because higher eco- 
nomic activity is likely to result in greater demand for space, which in turn, has an upward pressure on rents. Conversely, new supply coming onto the market is expected to offset (to a varying extent) the demand and weigh down the rent level. Hence, the model is initially formulated as the following function.

$$
R E N T=f[D(+), S(-)] .
$$

$D$ stands for demand side variables gdp, vas and $e m p$, and $S$ denotes supply proxies cons, starts, os and vac. Different $D$ and $S$ variables are only used in alternative specifications since according to a priori expectations, a strong correlation between the variables was discovered. This implies that incorporating several demand or supply side variables in the same specification risks unwanted multicollinearity.

\section{DATA}

Availability of relevant data chiefly defines the boundaries of the study in terms of geographical coverage and time span. Whilst the time series of many general economic variables are easily accessible today, the inadequacy of real estate sectorspecific data limits the research. Arising from that, we define the scope of the study to cover office rents in Helsinki CBD from 1986 to 2009. This is the longest running constant quality market rent time series available for any single submarket in the Finnish property market. The data set is provided by KTI Property Information Ltd, a Finnish property market information provider.

KTI maintains a Helsinki CBD office rental index, which is based upon newly signed lease agreements in the Helsinki CBD. It is generally accepted that new leases reflect the prevailing

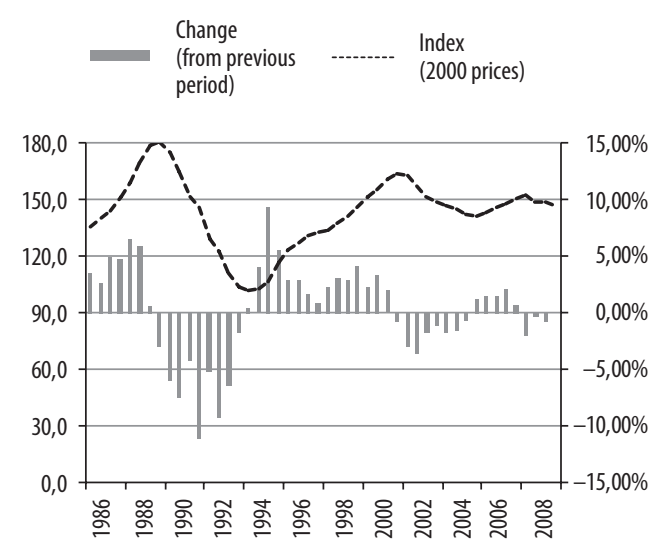

Fig. 2. Deflated Helsinki CBD rental index and its period-over-period change (index data: KTI) market conditions, and therefore the available index is well able to capture the changes in market rents. Nonetheless, it must be borne in mind that the index represents base line contract rents without considering rent-free periods, other temporal discounts, or investments paid by the landlord. As these factors are used as inducements to attract new tenants to a varying extent depending on the rental market conditions, the index is not likely to behave in an unbiased and coherent manner over time. Moreover, one might argue that landlords are inclined to allow for temporal rent reductions rather than a lower contract rent to artificially underpin the market rent level.

The authors of the current study acknowledge that a small geographical coverage is a serious constraint but lack of an index covering a larger geographical area provides no choice. On the other hand, as real estate markets are inherently highly segmented, a rent index of the entire metropolitan area would not be of much more use. In fact, individual indices for different submarkets allow for more meaningful examination, as substantial differences across alternative submarkets may exist.

The rental index is carried in semi-annual intervals so that the first period covers the months from March to August and the second one from September to February. The number of new leases per half a year period has historically varied roughly between 60 and 120 . In order to narrow down the superfluous volatility in the rental index, the leased area and business of the tenant are taken into account in constructing the index (Askelo, Laine 2003). The time series dates back to 1986 , which suffices the purpose of the current study. Since the index is provided in nominal terms, it was deflated with reference to the data point of March-August 2000 using the consumer price index (CPI) published by Statistics Finland. Figure 2. Deflated Helsinki CBD rental index and its period-over-period change (index data: KTI) depicts the development of the rental index (in March-April 2000 money) and the period-over-period change of the index in real terms.

Demand side variables ( $g d p$, vas and $\mathrm{emp}$ ) are all national series and provided in real terms by Statistics Finland covering the time period of Q1/1975 to Q3/2009. Using the national data series is a limitation, but as Hekman (1985) suggests, national variables could provide a sufficiently accurate picture of localized variables, unless they are not moving in distinct directions. If space users target their products in the national markets or to parties that are affected by national economic ac- 
tivity, the demand is argued to be at least partially affected by the national proxies (Hekman 1985). Moreover, Karakozova (2005) proposes that as approximately one-third of the national gross domestic product is created in the Helsinki region, the use of national figures is reasonable. Stemming from these arguments, the national proxies are considered to sufficiently explain occupier demand for the purpose of the current study. Consequently, seasonally adjusted national time series in quarterly intervals are used. To match the observation intervals with those of rental data, the original series were extrapolated so that intervals are equivalent. It is acknowledged that this manipulation process risks experiencing serial correlation in the later stages of the study (Gujarati, Porter 2010: 314-315).

With respect to supply side data, time series of office starts (starts), completions (cons) and stock (os) are comparably provided by Statistics Finland. Similar to demand proxies, starts (starts) and completions (cons) data are also available on a quarterly basis. Nevertheless, the available length of these time series is much shorter than that of demand variables since the data dates back to Q1/1992 with the latest available observation of Q3/2009. This is tolerable, albeit it would have been desirable to have time series long enough to go beyond the real estate market bubble and consequent crash of late 1980s and early 1990s. In contrast to starts and completions, office stock (os) data is provided in annual observations for the period of 1990 to 2008 so that each data point amounts to the total office stock at the end of the respective year. Similar to demand variables, data is extrapolated to match rent index intervals. The fourth investigated supply side proxy, the vacancy rate (vac), is provided for 1991 to 2009 by Catella Property Consultants. Its observation intervals are in line with the rental index resulting in no need for data massaging. Each of the aforementioned supply proxies are for the Helsinki office market.

\section{Stationarity testing}

To examine stationarity of the selected variables, the Augmented Dickey-Fuller (ADF) test was undertaken for logarithms of each of the variables. As the test results in Figure 4. Augmented DickeyFuller tests 4 show, each of the demand side variables ( $g p d$, vas and $e m p$ ) are stationary only in second difference I(2), whereas of the four supply side variables (cons, starts, os and vac), two are stationary in levels. It is also worth noting that the dependent variable rent proved stationary at a $1 \%$ significance level.

Figure 5. Logarithm of the original gdp time series with trend and detrended series generated by the Hodrick-Prescott filter 5 illustrates that a graphical inspection of the $g d p$ time series confirms that the series in fact exhibits a clear upward sloping trend, which likely gives rise to the nonstationarity discovered above. The other two demand proxies exhibited similar behaviour. To circumvent the problem, the demand time series were detrended using the Hodrick-Prescott (HP) filter, which segregates the trend from the time series. Consequently, the filtered demand time series (referred to as detrended in Figure 5. Logarithm of the original gdp time series with trend and detrended series generated by the Hodrick-Prescott filter were tested again for stationarity using the ADF procedure. Expectedly, each of the data series proved stationary in levels, gdp and sse at the $1 \%$ and vas at the 5\% confidence level. Arising from these results, the original demand side variables were superseded by the detrended variables.

Regardless that the detrended variables exhibit stationarity, initial estimations revealed the existence of a serial correlation in disturbance terms. As a result, the equation was re-formulated to model the changes rather than the levels of real rents. Correspondingly, alternative independent variables safe for office starts (starts) and completions (cons) that represent flow variables were differenced.

\begin{tabular}{|llllll|}
\hline Variable & Abbreviation & $\begin{array}{l}\text { Demand/ } \\
\text { supply }\end{array}$ & $\begin{array}{l}\text { Expected } \\
\text { sign }\end{array}$ & $\begin{array}{l}\text { Geographical } \\
\text { coverage }\end{array}$ & Source \\
\hline Gross domestic product & gdp & D & + & National & Statistics Finland \\
Added value of service sector & vas & D & + & National & Statistics Finland \\
Employment in financial, real & emp & D & + & National & Statistics Finland \\
estate and business services & & & & Helsinki & Statistics Finland \\
New office starts & starts & S & - & Helsinki & Statistics Finland \\
New office completions & cons & S & - & Helsinki & Statistics Finland \\
Office stock & os & S & - & Helsinki & KTI and Catella \\
Office vacancy & vac & S & - & & \\
\hline
\end{tabular}

Fig. 3. Demand and supply side variables that are incorporated in the model 


\begin{tabular}{|lcccccccc|}
\hline & rent & gdp & vas & emp & cons & starts & os & vac \\
\hline Level & $-3,92^{* * *}$ & $-2,21$ & $-1,76$ & 0,94 & $-3,21^{* *}$ & $-2,64^{*}$ & 0,26 & $-1,96$ \\
1. differenced & & $-1,49$ & $-1,75$ & $-2,36$ & & & $-2,91^{* * *}$ & $-2,87^{* * *}$ \\
2. differenced & & $-5,77^{* * *}$ & $-4,16^{* * *}$ & $-7,97^{* * *}$ & & & & \\
\hline
\end{tabular}

MacKinnon (1996) one-sided significance levels $10 \%, 5 \%$ and $1 \%$ are denoted ${ }^{*},{ }^{* *}$ and ${ }^{* *}$ respectively

Fig. 4. Augmented Dickey-Fuller tests

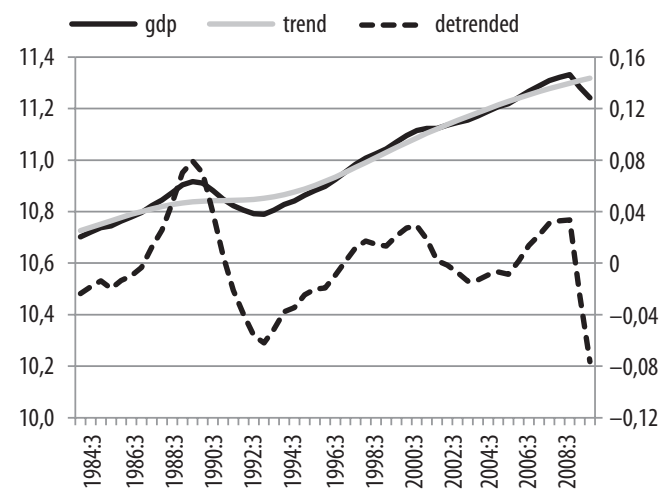

Fig. 5. Logarithm of the original gdp time series with trend and detrended series generated by the Hodrick-Prescott filter

Consequently, the following initial equation of real changes in Helsinki CBD office rents is formulated.

$$
\Delta \text { rent }_{t}=\beta_{1}+\sum_{i=0}^{K_{1}} \beta_{2 i} D+\sum_{i=0}^{K_{2}} \beta_{3 i} S+\varepsilon_{t},
$$

where $i=1,2, \ldots, T$.

Upper case letters denote logarithms of the demand $(D)$ and supply $(S)$ side variables, and D stands for the first difference. $\beta_{1}$ stands for the constant variable; $\beta_{2 i}$ and $\beta_{3 i}$ represent the partial coefficients; and $\varepsilon_{\mathrm{t}}$ stands for the disturbance term. Changes in real office rents in Helsinki CBD are hence subject to changes in three alternative demand proxies ( $g d p$, vas and emp), changes in os and vac and the level of supply flow variables cons and starts. Different variables are tested in alternative specifications in order to delineate the most influential reduced form demand supply model.

\section{RESULTS}

The estimation of the model was conducted with a general-to-specific approach that initially involves a large model that is rearranged and pared down to arrive at a statistically adequate and parsimonious final formulation. The procedure was actually repeated for each alternative model. The results of the estimation are represented in Table 1. Estimation of the alternative models. The table consists of three panels, each representing one of the al- ternative demand side variables. Correspondingly, within each panel there are five columns of which the right-most four display the alternative supply proxies. Therefore, altogether 12 alternative specifications were estimated and appropriately numbered.

Initially contemporaneous values and six lags (three years) of each explanatory variable were included, and the final lag structure was determined by the data during the estimation process. The most influential lags were selected and are displayed in the parenthesis after each investigated variable in the left-most column of the table. As proposed by the theory, an increase in economic activity should increase the space demand and consequently boost the rent level. In contrast, a higher level of space supply is expected to dampen market rents. Thus, positive coefficients for demand and negative coefficients for supply side variables are anticipated. Consequently, contemporaneous and lagged values of the variables that did not take an a priori expected sign were automatically left out. Besides, the variables that did not prove significant at a $10 \%$ confidence level were omitted from the table. Finally, the best-fitting equation within each specification was selected based upon the adjusted R-squared figure. Table 1. Estimation of the alternative models represents the estimated partial coefficients with respective t-values. In addition, adjusted R-squared figures, Durbin-Watson (DW) and F-statistics are reported.

As Table 1. Estimation of the alternative models illustrates, construction flow variables of new completions (cons) and office starts (starts) consistently outperformed office stock (os) and vacancy rate (vac) proxies. In general, the results show that changes in real office rents in Helsinki CBD are explained by the change in gross domestic product when lagged one-and-half years; the change in the value-add generated by the service sector; the change in employment in financial, real estate and business services in the previous year; the level of contemporaneous office completions (half-a-year in the past in one instance); and the level of office starts when lagged two years (one and half-a-year in the past in one instance). In broad terms, estima- 
Table 1. Estimation of the alternative models

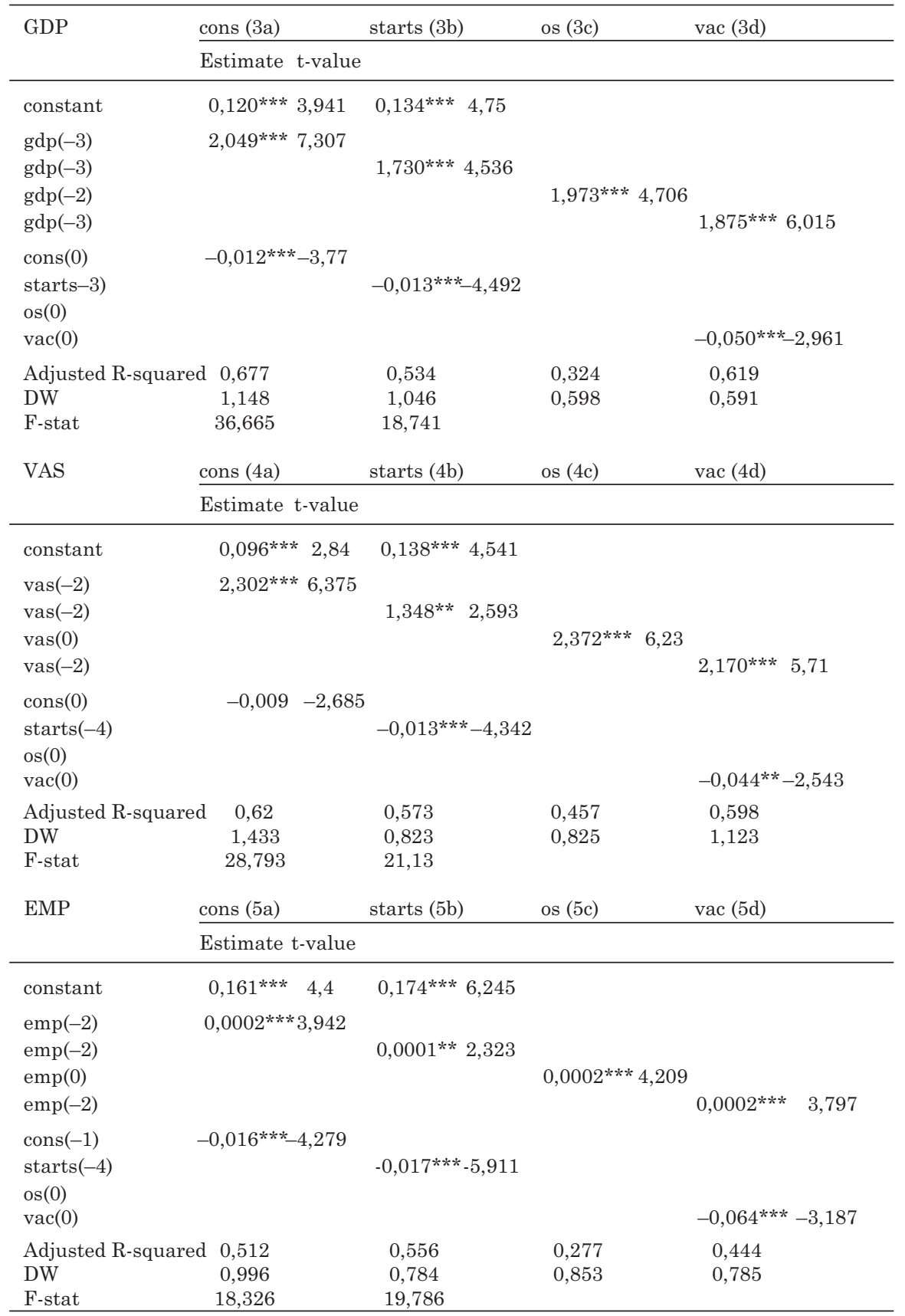

Each panel (GDP, VAS, EMP) represents one of the alternative demand side variables.

Further, each panel incorporates all the four supply proxies with respective equation number.

For example, the uppermost panel shows the equations $3 \mathrm{a}, 3 \mathrm{~b}, 3 \mathrm{c}$ and $3 \mathrm{~d}$.

The significance levels $10 \%, 5 \%$ and $1 \%$ are denoted with $*{ }^{* *}$ and ${ }^{* * *}$ respectively.

gdp, vas and emp denote changes of detrended demand variables.

os and vac denote changes of office stock and vacancy variables.

cons and starts are levels of these variables.

tion results suggest that all three demand proxies performed equally well when regressed with office starts and completions. The findings are generally in line with the previous studies represented in the literature to date. The result that gross domestic product has a significant impact on office rent movements conforms the findings of Gardiner and Henneberry (1989), Giussani et al. (1993), D’Arcy et al. (1997, 1999), and Karakozova (2005). The significance of employment variables similar to that employed in the current study is documented by Karakozova (2005) and Ng and Higgins (2007). To the authors' knowledge, the value-add created by the service sector has not been investigated in the literature to date with the exception of a very similar proxy of output in financial and business 
services employed by Karakozova (2005). Results conform to the findings of Karakozova (2005) in that respect as well.

When it comes to supply proxies, much less evidence of their impact on office rental variations has been documented by other researchers. However, this may be to a large extent attributable to the poor availability of supply data discussed above. In spite of that, the findings of D'Arcy et al. (1999) and Karakozova (2005) are in line with the results of the current study - that new office completions are able to capture some of the movements in office rents. However, in contrast to the findings of D'Arcy et al. (1999) and Karakozova (2005), the current study proposes that it is the contemporaneous value of new office completions rather than the values in the past that actually matters. At first, one might conclude that the Helsinki office market assimilates the new information of space coming into the market fairly swiftly. Nevertheless, it must be noted that in essence, office space is available as pre-lets long before it is actually completed. Hence, the findings are more likely to reflect the greater importance of marketing and the pre-letting period compared to greater market efficiency.

What is also interesting is that office starts performed well in the current study. To the authors' knowledge, there are no comparable findings in the previous literature. Admittedly, this finding is not that surprising, because in essence the starts variable expresses the same flow as the completions variable but in a more predictive manner. The finding may however be of great importance since office starts was found significant in two years in the past, and thus it could exhibit a superior forecasting ability.

While the estimated model (3a) outperformed the other specifications in terms of goodness of fit, the initial inspection of the Durbin-Watson figure

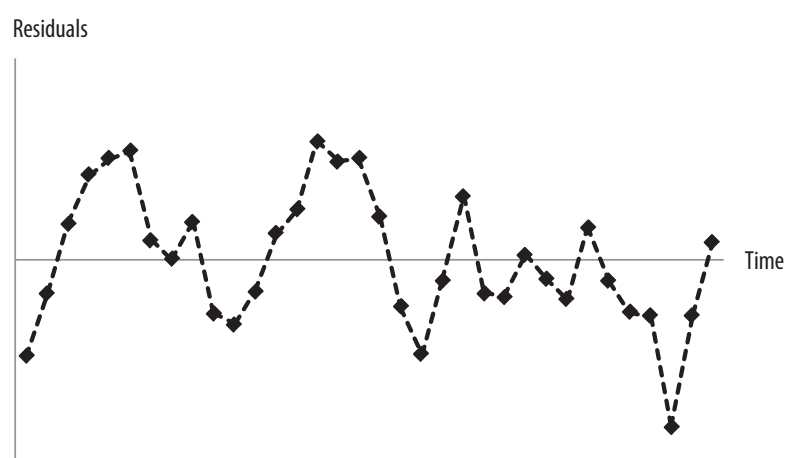

Fig. 6. Residuals of the estimated equation (3a) show positive serial correlation reveals strong positive first order serial correlation, an indication that past values of the variables may contain information about subsequent values (Hoesli, MacGregor 2000: 105). In fact, a relatively high $\mathrm{R}$-squared figure may be an illusion since positive autocorrelation is likely to inflate the figure (Brooks 2008: 150). The existence of positively serially correlated disturbance terms in the model (3a) is confirmed by Figure 6. Residuals of the estimated equation (3a) show positive serial correlation, in which the residuals are plotted against time. Also the more general Breusch-Godfrey LM test for serial correlation proposed strong existence of autocorrelated disturbance terms. Ramsey's RESET test for misspecification error revealed no signs of a wrong functional form or an omitted relevant variable. The generalised least squares (GLS) Cochrane-Orcutt procedure did not fully eliminate the problem of serial correlation.

Motivated by the persistent serial correlation problem in the model (3a) and the moderately robust DW statistic in conjunction with a relatively strong goodness of fit, the model (4a) was also elaborated in terms of autocorrelation, and as a result the Breusch-Godfrey LM test indicated no serial correlation. The absence of autocorrelation is further confirmed by a graphical inspection of Figure 7. Residual plot of the model (4a) indicates no/weak autocorrelation, which plots the residuals of estimated model (4a). In order to secure the adequacy of the model (4a), a number of other diagnostic tests were also performed. Table 2. Diagnostic tests on the estimated model (4a) displays the estimated test figures and respective critical values.

In addition, the model was tested for multicollinearity by inspecting the correlations between independent variables. In fact, a weak pair-wise correlation of 0.28 between the variables vas and cons was observed, but it was deemed to be suffi-

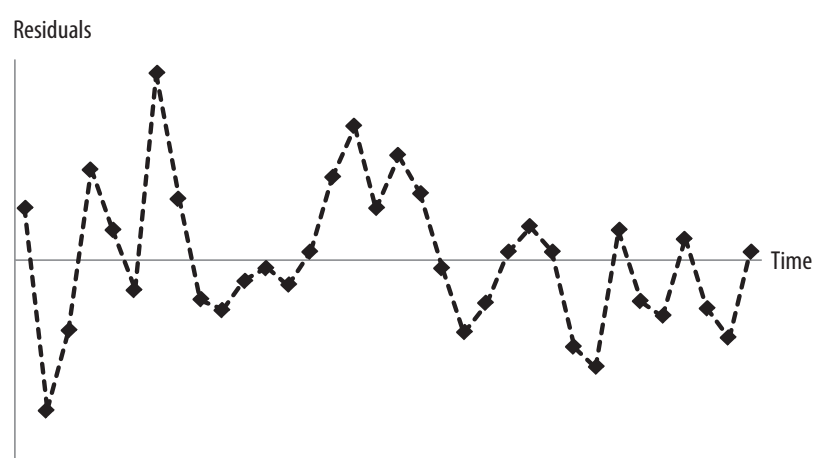

Fig. 7. Residual plot of the model (4a) indicates no/ weak autocorrelation 
Table 2. Diagnostic tests on the estimated model (4a)

\begin{tabular}{llll}
\hline & F-statistic* & p-value & Critical value \\
\hline Breusch-Godfrey LM test for serial correlation** & 2,623 & 0,115 & 3,32 \\
White's test for heteroskedasticity & 0,373 & 0,863 & 2,55 \\
Jarque-Bera test for non-normality & 0,996 & 0,608 & 4,16 \\
Ramsey's RESET test for misspecification & 0,502 & 0,484 & 4,16 \\
\hline
\end{tabular}

* Jarque-Bera statistics has a chi-square distribution

** up to second order

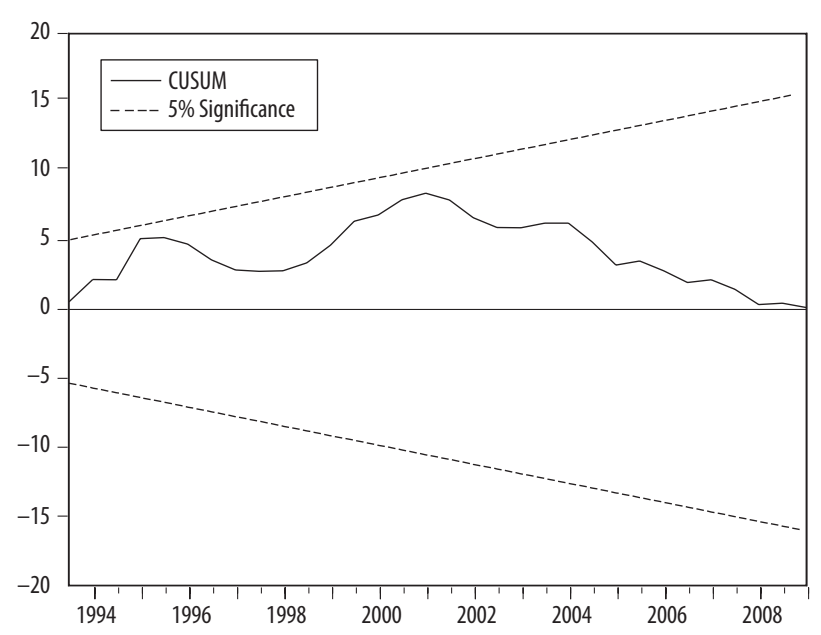

Fig. 8. CUSUM test graph for the model (4a)

ciently small not to distort the regression. Lastly, a CUSUM test was adopted for testing the model stability. The test results are represented in Figure 8. CUSUM test graph for the model (4a). Since the CUSUM line is well within the $5 \%$ confidence bands (straight dashed lines), the null hypothesis of parameter stability cannot be rejected; that is, the estimated parameters remain constant over the whole sample.

\section{EVALUATING MODEL'S FORECASTING ACCURACY}

Chaplin (1998a, 1998b) concluded that the relationship between historical fit and predictive fit is generally weak with reference to rental models. This implies that even though one is able to build a model with high explanatory quality, the model may fail to predict the future. In this section, the actual index and the predicted index produced by the fitted values are first contrasted. Secondly, out of the sample, a forecast is constructed for the period 2007-2009. Predictive fits are evaluated and compared to those of a few naïve forecasting methods, utilising some of the tests constructed for the purpose. Finally, an ex ante forecast for two periods forward is constructed.
Figure 9. Actual values of office rent index and fitted values based upon model (4a) illustrates the actual values of the Helsinki CBD office rent index and the fitted values predicted by model (4a) for the period 1992 to 2009. Fitted values are able to track the actual index extremely well until 1999. The Finnish national gross domestic product as well as the value-add generated by the service sector (vas) collapsed by the end of 1993 due to the deep recession sweeping over the country. At the same time, due to the lagging nature of the construction sector, a very large number of offices still came on the market, resulting in rapidly falling real rents. In contrast, while the revival in overall economic activity began in 1993, new office supply remained subdued for many years until 1997.

In fact, subsequent to several years of substantially low construction activity, new office supply surged during the late 1990s. Similarly, the valueadd of the service sector grew at a high pace until the so-called IT bubble burst in the very beginning of the new millennium. As a matter of fact, the fitted values fail to trail the actual rent index during 1998-2001. This implies that the massive office construction did not dampen the rent level as the model predicts. As a consequence, the fitted values suggested by the model (4a) remained at a distinctly lower level than the actual values

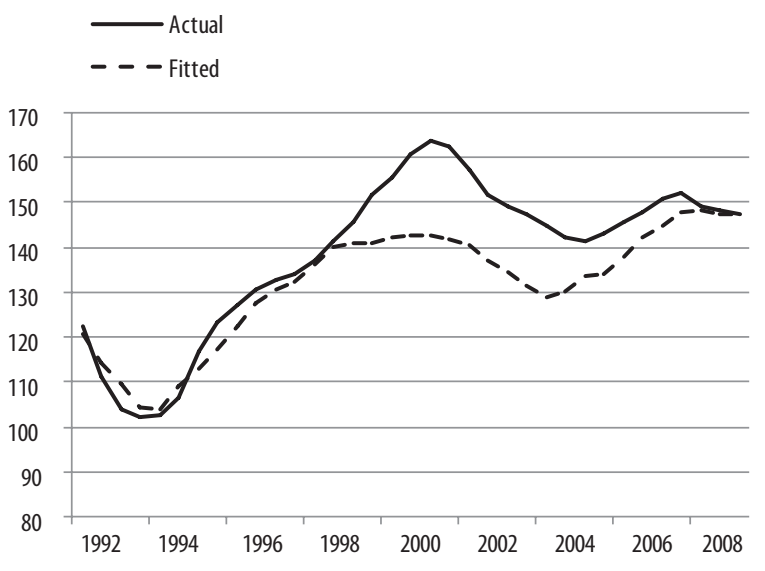

Fig. 9. Actual values of office rent index and fitted values based upon model (4a) 
almost until today. However, it must be noted that regardless of the difference in levels, the fitted values succeeded to follow quite well the directions of the actual rental index from 2002 onwards.

What is of particular interest to many real estate professionals is the model's ability to predict turning points in rental levels. In that respect, the model suffices to foresee the trough of the early 1990s as well as the turning point at the peak of 2001. Contrary to the good performance in the earlier years of the sample period, the fitted values of the model falsely anticipated that market rents would have turned up in 2004, a phenomenon that in fact occurred a year later. Furthermore, the fitted values missed the market rent peak in 2008 by half a year. All in all, the model failed to fully anticipate the Helsinki office market rent turning points.

To evaluate the forecasting performance of the model (4a) out of the sample, a forecast was produced for the period 2007:1-2009:1. The period includes five observations encompassing the market peak and subsequent fall in rents. The forecast was conducted recursively, so that the model was first estimated up to the period of 2006:2, after which the estimated model was used to forecast the rent level in the period of 2007:1. Thereafter the sample was rolled forward one period, the model was re-estimated and a new one-period-ahead forecast was carried out. This procedure was repeated until all five series of forecasts were undertaken. In addition, forecasts were produced by two naïve statistical methods: the double exponential smoothing method (DES) and the Holt-Winters procedure (H-W). In an upshot, these methods employ past observations of the time series being forecast to anticipate the subsequent periods' values (D'Arcy et al. 1999). As naïve procedures are atheoretical and purely mathematical, such methods are often used as benchmarks in evaluating the forecasting performance of a certain model (see, for example, Chaplin 1998a; D'Arcy et al. 1999; Matysiak, Tsolacos 2003).

Table 3. Out of the sample forecasts for the model (4a) and two naïve methods, 2007:1-2009:1 reports one-step-ahead projections for 2007:1 to 2009:1 produced by the competing methodologies. Interestingly, model (4a) did succeed in anticipating the market rent turning point in 2007:2 to 2008:1 somewhat better than the rival statistical methods. This finding conflicts with Chaplin (2000), who noted that the forecasting models could not consistently predict the correct direction of the change in series. It is acknowledged that only one turning point is considered here, which dilutes the results to some extent. However, it is also true that the H-W procedure also projected the start of the fall in rents, albeit not as precisely as the model. However, the double exponential smoothing method (DES) missed the turning point outright. Generally speaking, each of the three methods fairly consistently overpredicted the rent level throughout the two-and-a-half-year period.

When model (4a) was contrasted with the pure statistical methods using three conventional error measures, it still exhibited superior performance (see Table 4. Three alternative forecast accuracy measures). As the measures represent the size of the error, the smaller the estimated statistic is, the better the forecast efficiency. In fact, the model outperformed its competitors in all three assessment criteria. The results are contrary to the findings of Chaplin (2000), who concluded that rent forecasting models persistently lost to naïve competitor predictions. However, it must be borne in mind that the above forecast was produced with perfect foresight of the explanatory variables, new office completions in particular. Since according to model (4a), variations in real office rents are explained by contemporaneous office completions and the change in value-add in the service sector two periods prior, and the office supply variable must be estimated in order to produce an ex ante forecast using the model.

Given that the predictive performance of the model (4a) turned out to be at least satisfactory, an ex ante forecast two periods ahead was produced for 2009:2-2010:2. The reason for the forecast period selection was quite self-evident since the valued-add variable (vas) is a two-period lagged variable in the model. Therefore, only an estimation

Table 3. Out of the sample forecasts for the model (4a) and two naïve methods, 2007:1-2009:1

\begin{tabular}{|c|c|c|c|c|c|c|c|}
\hline \multirow[t]{2}{*}{ Period } & \multirow{2}{*}{$\begin{array}{l}\text { Actual } \\
\text { rent }\end{array}$} & \multicolumn{3}{|c|}{ Forecasts } & \multicolumn{3}{|c|}{ Percentage errors } \\
\hline & & $\mathrm{Eq}(4 \mathrm{a})$ & DES & H-W & Eq (4a) & DES & H-W \\
\hline $2007: 1$ & 151,1 & 150,4 & 149,2 & 150,0 & $-0,5 \%$ & $-1,3 \%$ & $-0,7 \%$ \\
\hline $2007: 2$ & 152,3 & 154 & 153,2 & 154,4 & $1,6 \%$ & $0,6 \%$ & $1,4 \%$ \\
\hline 2008:1 & 149,1 & 152,9 & 154,4 & 153,5 & $2,6 \%$ & $3,6 \%$ & $3,0 \%$ \\
\hline 2008:2 & 148,5 & 148,1 & 149,9 & 145,9 & $-0,2 \%$ & $0,9 \%$ & $-1,8 \%$ \\
\hline 2009:1 & 147,3 & 148,4 & 148,1 & 147,9 & $0,7 \%$ & $0,6 \%$ & $0,4 \%$ \\
\hline
\end{tabular}

Table 4. Three alternative forecast accuracy measures

\begin{tabular}{llll}
\hline & Eq (4a) & DES & H-W \\
\hline Mean absolute error (MAE) & 1,67 & 2,06 & 2,16 \\
Mean absolute percentage error (MAPE)\% & 1,12 & 1,38 & 1,44 \\
Mean squared error (MSE) & 4,44 & 7,07 & 6,42
\end{tabular}




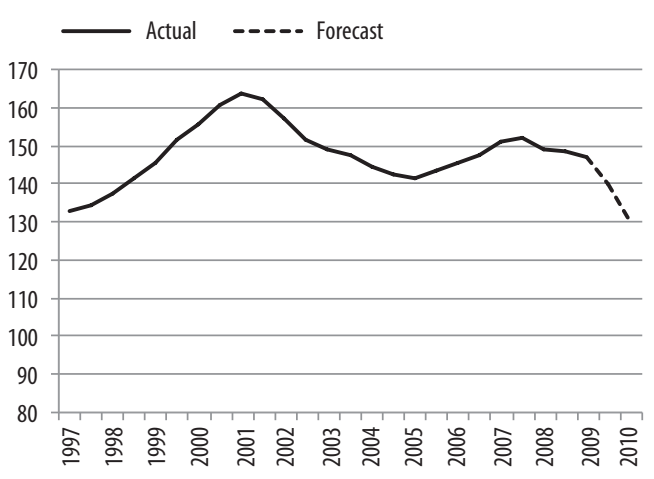

Fig. 10. Ex ante forecast of Helsinki CBD office rents until August 2010

of new office completions was required in order to generate the forecast. Preliminary information (provided by Statistics Finland) on new office completions for 2009:2: indicated 18,000 square metres of completed space for the first four months of the period. When that was extrapolated to cover the whole period, the estimation came to 27,000 square metres. Assuming that office construction works generally take three periods (i.e. one and half years) from start to completion, 2010:1 new completions were estimated on the basis of office starts data. The estimated figure of roughly 15,000 square metres indicates an expected substantial decrease in construction activity.

Figure 10. Ex ante forecast of Helsinki CBD office rents until August 2010 represents the ex ante forecast produced by model (4a). As the plot distinctly illustrates, the model anticipates a steep decline in real office market rents in Helsinki CBD over the coming half a year. In fact, the forecast index value (in real terms) for the period 2010:1 is 130.3 points, corresponding the $11 \%$ fall in rents compared to the level in 2009:1. In fact, this conforms to the collapse in economic activity in the recent past and the concurrent decline of construction activity in an outstanding manner.

\section{CONCLUSIONS}

Office market modelling has taken on several distinctive directions in the existing literature. There are numerous alternative methodologies that vary in terms of theoretical soundness, data intensiveness and complexity. One of the most frequently utilised approaches is the reduced form single equation method, which strives to identify certain macroeconomic variables that impact the rental adjustment process. The investigation of this approach suggests that gross domestic product has most regularly been found to be a significant demand-side variable in the rent determination process. As to supply side variables, poor data availability invariably undermines the results and in many instances precludes the inclusion of supply side variables from the final specification.

The aim of this article was to add to the existing literature on rental modelling by constructing a theoretically sound and statistically adequate model for central Helsinki office rents by testing three alternative demand side proxies with one of them being value-add of services sector. In addition, the study aimed to extend the rental modelling literature from more traditional property markets to under-researched office markets in Helsinki. Lastly, the authors of the current study intended to build up a model that not only provides for a strong historical fit but can effectively be used for forecasting purposes.

The current study discovers that variations in central Helsinki office rents are subject to changes in the national value-add in the services sector (vas) when lagged one year the and contemporaneous level of new office completions (cons) in the entire city of Helsinki. The findings with respect to new office completions generally conform to the existing research, whereas to the authors' knowledge, the added value of the service sector has not been successfully employed in the previous literature. The model has the relatively strong goodness of fit of 0.62 , which demonstrates that the independent variables are able to explain $62 \%$ of the variation in the dependent variable, the changes in real office rents in the Helsinki CBD.

In addition to a strong historical fit, the model exhibits good forecasting ability. The model outperformed two naïve forecasting methodologies when one-step-ahead forecasts over five periods were generated and subsequently contrasted to those of naïve methodologies. The estimated model was also able to trail the actual rent index extremely well up until 1999, after which the model could not foresee the steep hike and subsequent fall in rents from 1999 to 2003 . That time period is characterized by the so called IT bubble and its subsequent burst. Clearly, the variables incorporated in the model are not able to explain the market rent behaviour during that time, which undermines the robustness of the model for forecasting purposes. In addition, it must be noted that the above forecasts are produced with perfect knowledge of the independent variables, particularly the contemporaneous value of new completions. In order to produce ex ante forecasts, the value of that vari- 
able needs to be estimated, which undermines the model's forecasting capacity and the reliability of the produced forecasts.

The current study provides further insight into office rent modelling in the context of the Finnish real estate market, but an urgent need for additional research still remains. Existing property literature has thus far almost exclusively considered office markets, leaving other property segments (such as retail and logistics) with very little interest. Also, a number of rental modelling studies focus on so called 'first-tier' markets, whereas many smaller national or regional markets remain heavily under-researched. It is acknowledged that poor data supply continues to restrict the quantitative research and the current study does not make an exception with that respect. Further, the authors recognize that there is a spatial mismatch in the data used in the study which is a potential source of error in estimations. In order to overcome these limitations, a wider property market data offering is needed to facilitate further research.

\section{REFERENCES}

Askelo, S.; Laine, T. 2003. Toimitilojen vuokrat Helsingissä syksyllä 2002. [Online] Helsingin kaupungin tietokeskuksen verkkojulkaisuja 2003: 6 (in Finnish). Available at: www.hel2.fi/tietokeskus/julkaisut/pdf/03_12_30_askelo_vj6.pdf [accessed 9 January 2010]

Brooks, C. 2008. Introductory econometrics for finance. $2^{\text {nd }}$ ed. Cambridge University Press.

Catella. 2012. Property market report, autumn 2012 [online]. Available at: http://www.catella.fi/fi/10715.aspx [accessed 16 October 2012]

Chaplin, R. 1998a. The predictability of real office rents, Journal of Property Research 16(1): 21-49. http:// dx.doi.org/10.1080/095999199368247

Chaplin, R. 1998b. An ex post comparative evaluation of office rent prediction models, Journal of Property Valuation and Investment 16(1): 21-37. http://dx.doi. org/10.1108/14635789810205074

Chaplin, R. 2000. Predicting real estate rents: walking backwards into the future, Journal of Property Investment and Finance 18(3): 352-370. http://dx.doi. org/10.1108/14635780010339181

City of Helsinki Statistics. 2012 [online]. Available at: www.aluesarjat.fi [accessed 16 October 2012]

D'Arcy, E.; McGough, T.; Tsolacos, S. 1997. National economic trends, market size and city growth effects on European office rents, Journal of Property Research 14(4): 297-308. http://dx.doi. org/10.1080/095999197368546

D’Arcy, E.; McGough, T.; Tsolacos, S. 1999. An econometric analysis and forecasts of the rental cycle in the Dublin area, Journal of Property Research 16(4): 309-321. http://dx.doi.org/10.1080/095999199368067
Dobson, S.; Goddard, J. 1992. The determinants of commercial property prices and rents, Bulletin of Economic Research 44(4): 301-321. http://dx.doi. org/10.1111/j.1467-8586.1992.tb00549.x

Farrelly, K.; Sanderson, B. 2005. Modelling regime shifts in the city of London office rental cycle, Journal of Property Research 22(4): 325-344. http://dx.doi. org/10.1080/09599910600558553

Gardiner, C.; Henneberry, J. 1989. The development of a simple regional office rent prediction model, Journal of Property Valuation and Investment 7(1): 36-52. http://dx.doi.org/10.1108/EUM0000000003257

Giussani, B.; Hsia, M.; Tsolacos, S. 1993. A comparative analysis of the major determinants of office rental values in Europe, Journal of Property Valuation and Investment 11(2): 157-173. http://dx.doi. org/10.1108/14635789310031487

Gujarati, D.; Porter, D. 2010. Essential of econometrics. $4^{\text {th }}$ ed. McGraw-Hill International Edition.

Hekman, J. 1985. Rental price adjustment and investment in the office market, Real Estate Economics 13(1): 32-47. http://dx.doi.org/10.1111/15406229.00339

Hendershott, P.; Lizieri, C.; Matysiak, G. 1999. The workings of the London office market, Real Estate Economic 27(2): 365-387. http://dx.doi.org/10.1111/15406229.00777

Hendershott, P.; MacGregor, B.; White, M. 2002a. Explaining real commercial rents using an error correction model with panel data, Journal of Real Estate Finance and Economics 24(1/2): 59-87. http://dx.doi. org/10.1023/A:1013930304732

Hendershott, P.; MacGregor, B.; Tse, R. 2002b. Estimation of the rental adjustment process, Real Estate Economics 30(2): 165-183. http://dx.doi. org/10.1111/1540-6229.00036

Hendershott, P.; Lizieri, C.; MacGregor, B. 2010. Asymmetric adjustment in the city of London office market, Journal of Real Estate Finance and Economics 41(1): 80-101. http://dx.doi.org/10.1007/s11146-0099199-6

Ho, W. 2005. Modelling the dynamics of the Hong Kong office market under economic structural change, Environment and Planning B: Planning and Design 32(1): 111-125. http://dx.doi.org/10.1068/b3198

Hoesli, M.; MacGregor, B. 2000. Property investment principles and practice of portfolio management. $1^{\text {st }}$ ed. Pearson Education Limited.

Hui, E.; Yu, K. 2006. The dynamics of Hong Kong's office rental market, International Journal of Strategic Property Management 10(3): 145-168. http://dx.doi.or g/10.1080/1648715X.2006.9637550

Karakozova, O. 2005. Modelling and forecasting property rents and returns. Doctoral thesis. Publications of the Swedish School of Economics and Business Administration, No 149. Helsinki.

Ke, Q.; White, M. 2009. An econometric analysis of Shanghai office rents, Journal of Property Investment and Finance 27(2): 120-139. http://dx.doi. org/10.1108/14635780910937836

Keogh, G. 1994. Use and investment markets in British real estate, Journal of Property Valua- 
tion and Investment 12(4): 58-72. http://dx.doi. org/10.1108/14635789410069980

KTI. 2010. The Finnish Property Market 2010 [online]. Available at: www.kti.fi/kti/doc/ajankohtaista/KTI_ FMP_Final_net.pdf [accessed 16 October 2012]

Matysiak, G.; Tsolacos, S. 2003. Identifying shortterm leading indicators for real estate rental performance, Journal of Property Investment and Finance 21(3): 212-232. http://dx.doi. org/10.1108/14635780310481658

McGough, T.; Tsolacos, S. 1995. Forecasting commercial rental values using ARIMA models, Journal of Property Valuation and Investment 13(5): 6-22. http:// dx.doi.org/10.1108/14635789510147801

McGough, T.; Tsolacos, S.; Olkkonen, O. 2000. The predictability of office property returns in Helsinki, Journal of Property Investment and Finance 18(6): 565585. http://dx.doi.org/10.1108/14635780010357541

Mouzakis, F.; Richards, D. 2007. Panel data modelling of prime office rents: a study of 12 major European markets, Journal of Property Research 24(1): 31-53. http://dx.doi.org/10.1080/09599910701297713

Ng, B. F.; Higgins, D. 2007. Modelling the commercial property market: an empirical study of the Singapore office market, Pacific Rim Property Research Journal 13(2): 176-193.

Orr, A.; Jones, C. 2003. The analysis and prediction of urban office rents, Urban Studies 40(11): 2255-2284. http://dx.doi.org/10.1080/0042098032000123286

RICS. 1994. Understanding the property cycle: economic cycles and property cycles main report. The Royal
Institution of Chartered Surveyors (RICS). London: RICS.

Rosen, K. 1984. Toward a model of the office building sector, Real Estate Economics 12(3): 261-269. http:// dx.doi.org/10.1111/1540-6229.00322

Stevenson, S. 2007. Exploring the intra-metropolitan dynamics of the London office market, Journal of Real Estate Portfolio Management 13(2): 93-98.

Stevenson, S.; McGarth, O. 2003. A comparison of alternative rental forecasting models: empirical tests on the London office market, Journal of Property Research 20(3): 235-260. http://dx.doi. org/10.1080/0959991032000162338

Tse, R.; Webb, J. 2003. Models of office market dynamics, Urban Studies 40(1): 71-89. http://dx.doi. org/10.1080/00420980220080171

Wheaton, W. 1987. The cyclic behaviour of the national office market, Real Estate Economics 15(4): 281-299. http://dx.doi.org/10.1111/1540-6229.00433

Wheaton, W.; Torto, R. 1988. Vacancy rates and the future of office rents, Real Estate Economics 16(4): 430-436. http://dx.doi.org/10.1111/1540-6229.00466

Wheaton, W.; Torto, R.; Evans, P. 1997. The cyclic behaviour of the greater London office market, Journal of Real Estate Finance and Economics 15(1): 77-92. http://dx.doi.org/10.1023/A:1007701422238

White, M.; Mackay, D.; Gibb, K. 2000. A comparative analysis of Scottish property rents, Journal of Property Investment and Finance 18(3): 332-351. http:// dx.doi.org/10.1108/14635780010338326 